AFTER a year notable for set-backs, the Soviet space programme has made a successful start to 1975 with the Soyuz-17/Salyut-4 mission. As well as testing out some modifications to the hardware, notably the new autonomic navigation system, the two-man team carried out a wide range of biological and physical experiments.

Although some of these experiments are now of a fairly routine naturemedical tests on the cosmonauts and monitoring the ultraviolet radiation of the Sun, for example-some of them have a more adventurous quality. Among these must be classed the 'Filin' experiment, designed by a team from the Shternberg Astronomical Institute of Moscow State University. This comprises a group of spectrometers for monitoring X-radiation of stellar origin in the $0.2-10 \mathrm{keV}$ range, together with telescopes with a field of view of approximately $1^{\circ}$, intended to correlate the spectrometer readings with visual observations. It is hoped that the results of this project may provide information on white dwarfs and neutron stars. Special attention was given to Rigel and to the remains of the Vela supernova. A somewhat speculative Pravda article (January 24) suggests that this experiment may even throw some light on the vexed subject of black holes. During one orbit simultaneous infrared and X-ray observations were made of the characteristics of the background radiation along the Galactic meridian.

Nearer home, the 'Spektr' experiment studied the ambient conditions of the spacecraft, and in particular, the effect of its constant bombardment by charged particles. A special apparatus, produced by one of the Instrumentation Institutes of the Space Research Institute of the Soviet Academy of Sciences, consisted of two subsystems -one to analyse the incident flow of particles and the other to analyse those emitted after impact. These measure. ments, which were recorded on tape sc as not to overload the communications channels to ground control, are intended, not only for use in plotting a quantitative model of the upper ionosphere, but also for the design of future spaceships and orbital craft.

Solar observations, now a routine part of any orbital mission, included a series of spectrography and diffraction spectrometry experiments, which automatically recorded the ultraviolet radiation from the entire solar disk, while at the same time flight engineer Grechko photographed sunspots and prominences.

Later investigations with the solar telescope included an experiment in which protective coatings were deposited on the surface of the mirrors, can "at the same tome seek the 'fingerin order to assess the possibilities of prints' of the molecular components of creating and restoring good optical matter on the planets and can also look properties to mirrors subjected to bom- under definite layers of the atmosphere bardment erosion.

Another routine experiment-the recording of infrared radiation from the Earth and Moon-on this occasion included a special "deep-cooling"

\section{Soviet spacemen's programme} from Vera Rich
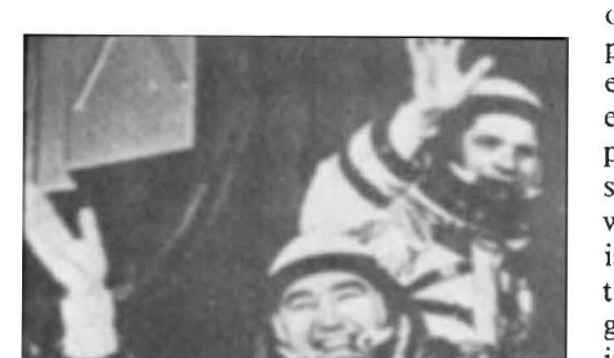
surrounding the planets of the Solar system" (Pravda, January 30, 1975). The ITS-K experiment, in fact, is a continuation of a programme begun by the Lebedev Physics Institute, back in 1968, using high altitude $(500) \mathrm{km})$ rocket observations.

Visual photography (both black-andwhite and colour) is also traditionally presented by the planners as a valuable contribution to "the study of the environment and the solution of individual problems in the interests of the national economy". On this mission, special emphasis has been placed on such photography, since, in general, the study of such photographs taken in winter has been somewhat ignored. It is hoped that the snow-cover may throw into strong relief ravines and gullies and other features of geological interest. Special attention has been given to the photography of Soviet Central Asia and Kazakhstan, and the south-western European region of the USSR including the Caucausus. Unfortunately for the conservationists, weather conditions prevented photography of the Baikal area.

The on-board experiments (codenamed 'Oasis') included a number of genetic, embryological, physiological and biotechnical projects using insects, microorganisms, tissue cultures and higher plants. Special mention is made of Drosophila (once legislated out of Soviet science under Lysenkoism) and Chlorella. Biological experiments on the cosmonauts themselves included a series of tests monitoring the respiratory and cardiovascular systems using graded loads, a "special vacuum suit" and a rotating chair. On the nineteenth day of the flight, an ultrasonic device was used to determine changes in the density of bone tissues, and blood samples were taken for postflight analysis.

Grechko and Gubarev board Soyuz-17.

Also at the biological level, considerable importance was laid on the recycling of water (from atmospheric moisture), to be used by the cosmonauts for drinking and food preparation.

At the beginning of this mission, it

system "sublimation cold accumulator", to maintain the sensitive element of the infrared telescope-spectrometer at the required temperature. These infrared observations of Earth always form an important part of Soviet orbital missions, since they can be justified in terms of the national economy as a means of surveying resources. In the Salyut-4 programme, however, infrared observations were also used to investigate cosmic phenomena. Salyut 4 carried a special infrared device, the ITS-K, which, in the words of Dr M. N. Markov of the Lebedev Physics was stressed by Major-General Georgii Beregovoi, Head of the Cosmonaut Training Programme, that it should not be considered simply as a preparation for the forthcoming Soyuz-Apollo project. Nevertheless, when the Soviet team for the project flew to Houston on February 8, for the next round of preparatory talks, there can be little doubt that both sides saw the success of the Salyut-4 mission as a promising augury for the joint venture. 